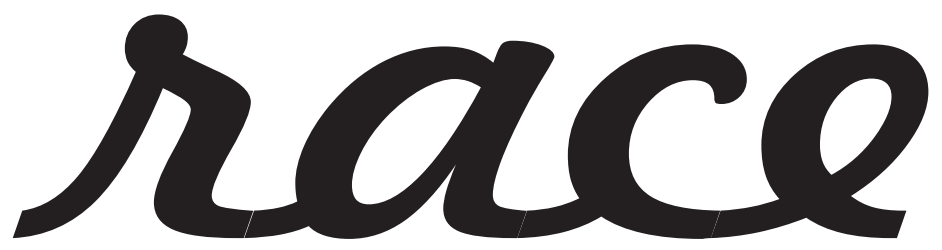

\title{
revista de administração, contabilidade e economia
}

v. 17, n. 2, maio./ago. 2018

Agosto 2018

DOI desta edição:

http://dx.doi.org/10.18593/race.v17i2

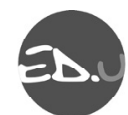

Editora Unoese

ISSN on-line 2179-4936 


\section{R118 RACE : Revista de Administração, Contabilidade e Economia / Universidade do Oeste} de Santa Catarina - Vol. 1, n. 1 (jan.-dez. 2002)- . - Joaçaba : Ed. Unoesc, 2002v. : il. ; $23 \mathrm{~cm}$.

Anual, 2002-2005; semestral, 2006--2013; Quadrimestral, 2014-

Qualis Capes B3

ISSN 1678-6483 - ISSN on-line 2179-4936

1. Administração - Periódicos. 2. Contabilidade - Periódicos. 3. Economia Periódicos. I. Universidade do Oeste de Santa Catarina.

Rua Getúlio Vargas, 2125, Bairro Flor da Serra, CEP 89600-000 - Joaçaba - Santa Catarina, Brasil Fone: (55) (49) 3551-2065 - Fax: (55) (49) 3551-2004 - editora@unoesc.edu.br

\author{
Editora Unoesc \\ Coordenação \\ Tiago de Matia \\ Editor \\ Dra. leda Margarete Oro \\ race@unoesc.edu.br \\ Editores-Adjuntos \\ Cláudia Sofia Frias e Juliano Danilo Spuldaro \\ race@unoesc.edu.br
}

\section{Conselho Editorial}

Dr. Silvio Santos Junior, Unoesc - Universidade do Oeste de Santa Catarina, Brasil Prof. Dr. Joaquim Filipe Ferraz Esteves de Araújo, Universidade do Minho, Portugal Dr. Enrique José Varela Alvarez, Universidade de Vigo, Espanha

Dra. Denise Del Prá Netto Machado, Universidade Regional de Blumenau Dr. Sérgio Luiz Lessa Gusmão, Pontifícia Universiade Católica do Rio Grande do Sul

Dr. Carlos Ricardo Rossetto, UNIVALI, Brasil

Dr. Eduardo Damião da Silva, Pontifícia Universidade Católica do Paraná

Dr. Sandro Bergue, Universidade de Caxias do Sul

Dr. Fernando Luiz Abrucio, FGV/SP

Dra. Eliane Salete Filippim, Unoesc

Dr. Jair do Amaral Filho, UFC - CE

Dr Decio Zylbersztajn, Universidade de São Paulo, Brasil

\section{Comissão Editorial}

Dr. Aldo Leonardo Cunha Callado, Universidade Federal da Paraíba, Brasil Dr. Gilberto Montibeller Neto, Kingston Business School Dra. Mônica Bragaglia, Centro Universitário Metodista do IPA Dr. Alcides Goularti Filho, Universidade do Extremo Sul Catarinense, Brasil Dr Luciano Munck, Universidade Estadual de Londrina

Dr Clóvis Antônio Kronbauer, Universidade do Vale do Rio dos Sinos, Brasil Dr. Daniel Poletto Tesser, Universidade Tecnológica do Paraná, Brasil Dra. Rosalía Martinez García, Universidad Pablo de Olavide de Sevilla, Espanha Dr Decio Zylbersztajn, Universidade de São Paulo, Brasil

Dr. Hironobu Sano, Universidade Federal do Rio Grande do Norte, Brasil

Dr. José Elmar Feger, Universidade Federal do Paraná - UFPR, Brasil

Dra. Arilda Schimidt Godoy, Universiade Presbiteriana Mackenzie

Dra Marta Zambiasi, Universidade Presbiteriana Mackenzie

Dr. Anielson Barbosa Silva, Universidade Federal da Paraíba, Brasil

\section{Revisão linguística e metodológica: Gilvana Toniélo}

Projeto gráfico: Daniely Akemi Terao

Arte da capa: Vanessa Cristhina Lesnieski

Indexação: Spell - Scientific periodicals eletronic library

Portal de Periódicos Capes

Directory of Open Access Journals - DOAJ

Sistema Regional de Información en Línea para Revistas Científicas de América Latina, el Caribe, España y Portugal (Latindex) - México

Universidad de La Rioja, Proyecto Dialnet - España

Citas Latinoamericanas en Ciencias Sociales y Humanidades (Clase) - México

Repositório Científico de Acesso Aberto de Portugal - RCAAP

Journal TOCs

Journals for Free

Biblat - Bibliografia latinoamericana

Sistema Eletrônico de Editoração de Revistas

Biblioteca do Conselho da Justiça Federal

Sumários.org - Sumários de Revistas Brasileiras

Indexação Compartilhada de Artigos de Periódicos (ICAP)

Diadorim

Foco e Público-Alvo: O foco da RACE é a publicação de estudos referentes à área da gestão pública ou privada, especialmente contemplando a contribuição científica e a compreensão da temática da sustentabilidade nas suas dimensões: econômica, ambiental e social. Os estudos submetidos à RACE deverão ter como escopo a análise dos diversos fatores de competitividade e de sustentabilidade das organizações, dos processos ou dos empreendimentos. sustentabilidade abrigando estudos relacionados à Administração, à Contabilidade e à Economia. 